\title{
The structure and protective properties of IFHANAL conversion coatings on aluminum alloys
}

\author{
Yu.A. Kuzenkov and S.V. Oleynik* \\ A.N. Frumkin Institute of Physical Chemistry and Electrochemistry, Russian Academy \\ of Sciences, Leninsky pr. 31, Moscow, 119071 Russian Federation \\ *E-mail: osvpkzifh@mail.ru
}

\begin{abstract}
The chemical oxidation in a chromate-free IFHANAL converting solution leads to the formation of conversion coatings with different thicknesses on aluminum (1010) and its alloys $(5154,6063,2024,7075)$. According to the data of polarization measurements in chloride solutions, the thickness of the coatings under study is not a determining factor in their protective ability. A significant increase in the protective properties of the coatings obtained is observed upon filling of the coatings in a solution of IFKhAN-25 corrosion inhibitor. This effect of coating filling is associated with changes in their structure during the hydration of surface oxides. According to X-ray phase analysis data, the conversion coating on 1010 aluminum alloy in its initial state consists of amorphous aluminum oxide phases. Filling of the coating in distilled water and in a solution of corrosion inhibitor equally changes the phase state of the surface oxide. The level of oxide crystallization increases in both cases, but the effect of the inhibitor on the process of oxide hydration is not observed. Perhaps, the crystallization of the oxide promotes adsorption of the inhibitor and increases the protective properties of the filled coating. Filling of conversion coatings on the $\mathrm{Al}-\mathrm{Mg}$ alloys studied also modifies the phase state of surface oxides, making them less amorphous. The corrosion inhibitor in filling solutions is directly involved in the process of oxide hydration in conversion coatings on $\mathrm{Al}-\mathrm{Mg}$ alloys, contributing to the strengthening of their protective properties. During the filling of more complex hetero-oxide structures in $\mathrm{Al}-\mathrm{Mg}-\mathrm{Cu}(\mathrm{Zn})$ alloys, the corrosion inhibitor adsorption makes a prevalent contribution to the increase in protective properties.
\end{abstract}

Key words: aluminium alloys, conversion coatings, X-ray phase analysis, filling of coatings, corrosion inhibitor.

Received: August 6, 2018. Published: December 5, 2018

doi: $\underline{10.17675 / 2305-6894-2018-7-4-13}$

\section{Introduction}

A number of factors determine the functional characteristics of protective coatings on metals, the composition and structure playing the decisive role among these factors. The latter fully applies to the conversion coatings (CC) formed by both components of the converting medium and the products of dissolution of the metal (alloy). Given the 
multiphase nature of aluminum alloys used in aircraft construction, the structure and protective properties of conversion coatings on them depend largely on the heterogeneity of the substrate. This is clearly demonstrated by a number of studies [1-5] of the chromate conversion coatings composition and structure, the mechanism of formation of which continues being studied despite their steady replacement with chromate-free technologies. Apparently, this is due to the known universality of chromate coatings and the identification of the features of their formation and structure on different types of alloys can contribute to the progress in the development of chromate-free processes. As shown in [1-3], formation of conversion chromate coatings on the high-strength copper-containing alloys is characterized by structural heterogeneity due to the advanced formation of the coating at the initial stages of growth on $\mathrm{Al}-\mathrm{Cu}-\mathrm{Mg}$ or $\mathrm{Al}-\mathrm{Cu}-\mathrm{Fe}-\mathrm{Mn}$ phases compared to the alloy matrix. The adsorption of chromate ions occurs at a later stage of coating growth, when it extends to the matrix and becomes loose or porous [1]. When replacing chromates in converting compositions with trivalent chromium compounds on the surface of 7075 alloy, the formation of the coating also began at intermetallic phases [6,7]. A similar approach of the formation of conversion coatings is considered and the use of fluozirconate or fluotitanate solutions, as well as compositions based on compounds of rare earth elements [8-12]. The structure of conversion coatings during oxidation of $\mathrm{Al}-\mathrm{Mg}$ alloys in molybdate solutions varied from amorphous or fine-crystalline to large-crystal $(10-30 \mu)$ with increasing magnesium content in the alloy, and in the composition of the heteroxide layer, the content of molybdenum oxides reached $30 \%$ wt. [13]. The greatest resistance to pitting corrosion had a coating on A1010. To be noted that the filling of such coatings in the corrosion inhibitors solutions increased to varying degrees their resistance against pitting corrosion in chloride media. In this regard, the aim of this work is to study the role of structural changes in conversion coatings on aluminum alloys when filled in corrosion inhibitors solutions.

\section{Materials and methods}

$\mathrm{CC}$ was formed on samples from aluminum alloys 1010 (AV00), 5154 (AMg-3), 6063 (AD-31), 2024 (D16) and 7075-T2 (V95T2) in the form of plates $(20 \times 50 \mathrm{~mm})$. Preparation of the surface of the samples before oxidation included the following operations: grinding with sandpaper of different grit, degreasing with ethanol, etching $(1 \mathrm{~min}$ in $10 \% \mathrm{NaOH}$ solution at $t=65-67^{\circ} \mathrm{C}$ ), washing with hot distilled water, desmutting ( $3 \mathrm{~min}$ in $50 \%$ $\mathrm{HNO}_{3}$ solution), washing with water and drying. After exposure during the day in an desiccator with $\mathrm{CaCl}_{2}$, the samples were weighed on an analytical balance $( \pm 0.0001 \mathrm{~g})$ and then oxidized in a converting solution. After oxidation, they were washed with distilled water, dried in air at room temperature for at least 12 hours and weighed. Thickness of coatings was determined by the gravimetric method after their removal from the sample by etching in a standard chromate-phosphate solution [13]. The filling of the coatings was carried out in distilled water or in a corrosion inhibitor solution for up to $1 \mathrm{~h}$ at $t=95 \pm 2^{\circ} \mathrm{C}$. 
Anodic polarization curves of the alloys with $\mathrm{CC}$ (working surface $0.5 \mathrm{~cm}^{2}$ ) were obtained in a borate buffer solution ( $\mathrm{pH}$ 7.36) containing $0.01 \mathrm{M} \mathrm{NaCl}$ at $t=20 \pm 2^{\circ} \mathrm{C}$ in a standard three-electrode cell. Pyrographite was used as an auxiliary electrode, and a saturated chloride-silver electrode was used as a reference electrode. The polarization of the electrodes $(1 \mathrm{mV} / \mathrm{s})$ began after the establishment of the corrosion potential of the electrode $\left(E_{\mathrm{c}}\right)$ after 10-20 min of their exposure in the test solution and closed after a sharp increase of current density on the polarization curves as a result of the breakdown of the $\mathrm{CC}$ on reaching the pit formation potential $\left(E_{\mathrm{pt}}\right)$. All values of potentials were recalculated to the standard hydrogen scale.

The diffractograms of CC on aluminum alloys were obtained on an EMPYREAN Xray diffractometer (Pananalitical, $\mathrm{UK}$ ) in the reflection geometry using $\mathrm{Cu}_{\mathrm{k} \alpha}$ radiation in combination with a Ni filter.

\section{Experimental results and discussion}

In the initial state, the most of the $\mathrm{CC}$ on the investigated aluminum alloys obtained in the IFHANAL-3 converting solution do not effectively inhibit their local anodic activation in chloride media. As seen in Figure 1, the value of the passivity domain $\left(E_{\mathrm{pt}}-E_{\mathrm{c}}\right)$ of samples with CC on alloys 5154, 6063, 2024 and 7075-T2 at a comparable coating thickness (3$5 \mu \mathrm{m}$ ) is not more than $300 \mathrm{mV}$. On technically pure aluminum (1010) in similar conditions, a thinner CC $(1.3 \mu \mathrm{m})$ is formed, which, however, is characterized by a much larger passivity domain compared to other alloys. Probably, in this case resistance to pitting formation in chloride media is largely due to the structure and composition of $\mathrm{CC}$, not its thickness. It is proved by a significant increase of the passivity domain of all the studied CC (Figure 1) after filling in the solution of a known corrosion inhibitor IFKhAN25 [14]. As is known, the adsorption of IFKhAN-25 enhances the protective properties of CC [15], but in the process of filling coatings its hydration occurs, which may be accompanied by structural changes. Indeed, as follows from the data of X-ray phase analysis of CC obtained on technical aluminum 1010 (Figure 2), there is a three-wide peak of aluminum oxide, with the first and second peaks merging into one wide peak. Such blurred peaks indicate that this phase is amorphous. The filling of the coating in water and in solution of the inhibitor IFKhAN-25 modifies the coating, "removing" the second peak of aluminum oxide - the broadest and thus most amorphous. This way, a three-phase oxide turns into a two-phase one. It is hydration during filling, which influence on the protective properties of the coating is present in this case, but the contribution of corrosion inhibitor to this process in this case is not traced.

Another pattern is observed on the CC diffractograms on the 5154 alloy (Figure 3). It initially formed a single-phase amorphous conversion coating of aluminum oxide. This coating has weak protective properties (Figure 1), which can be enhanced by filling in a solution of corrosion inhibitor IFKhAN-25. As can be seen from the diffractogram of the water-filled coating hydration of the oxide film, unlike the coating on aluminum 1010, has 

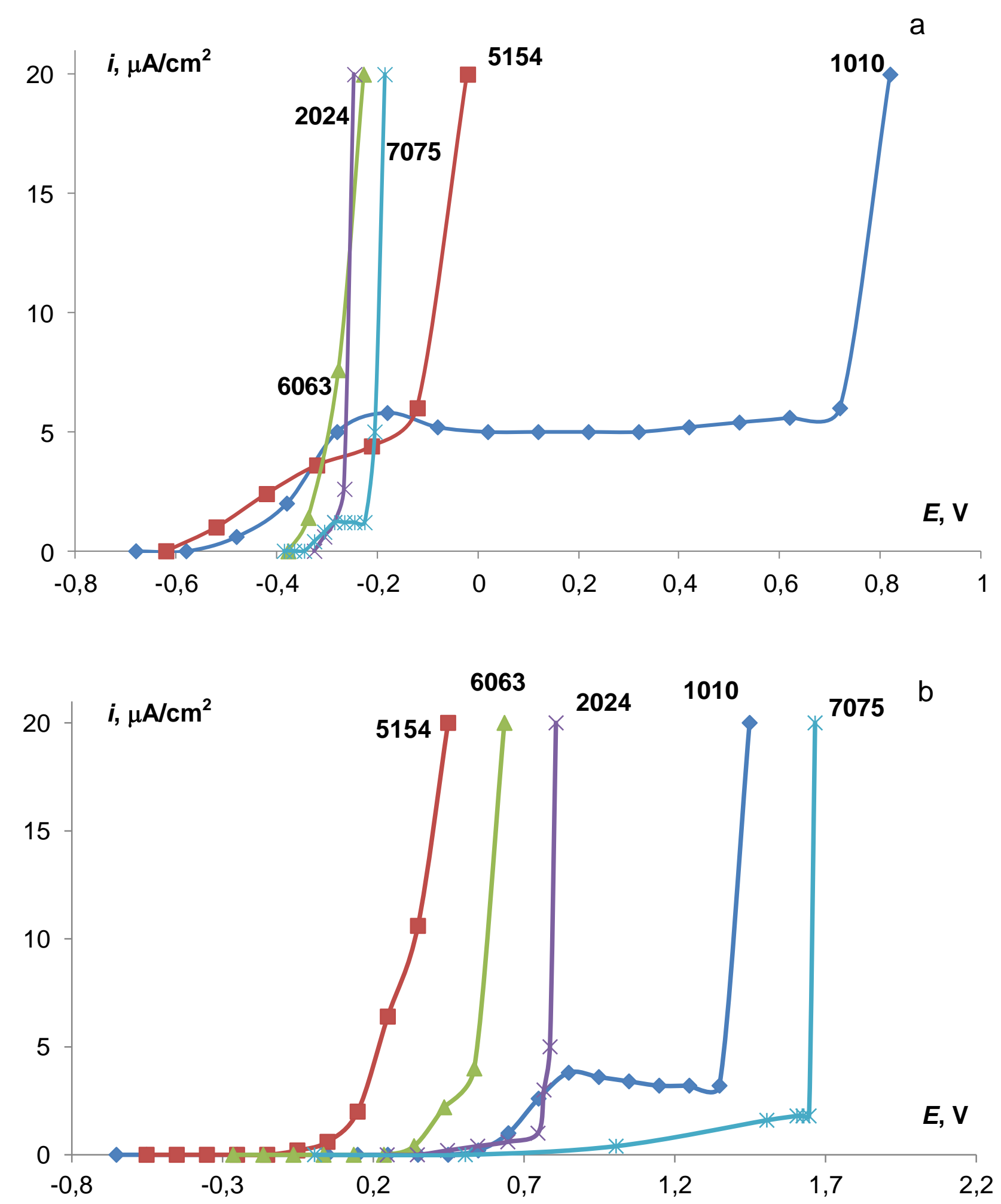

Figure 1. Anodic polarization curves of different aluminum alloys in $0.1 \mathrm{M} \mathrm{NaCl}(\mathrm{pH}$ 7.4) with a conversion coating (a) and the subsequent filling in the IFHAN-25 solution (b). 


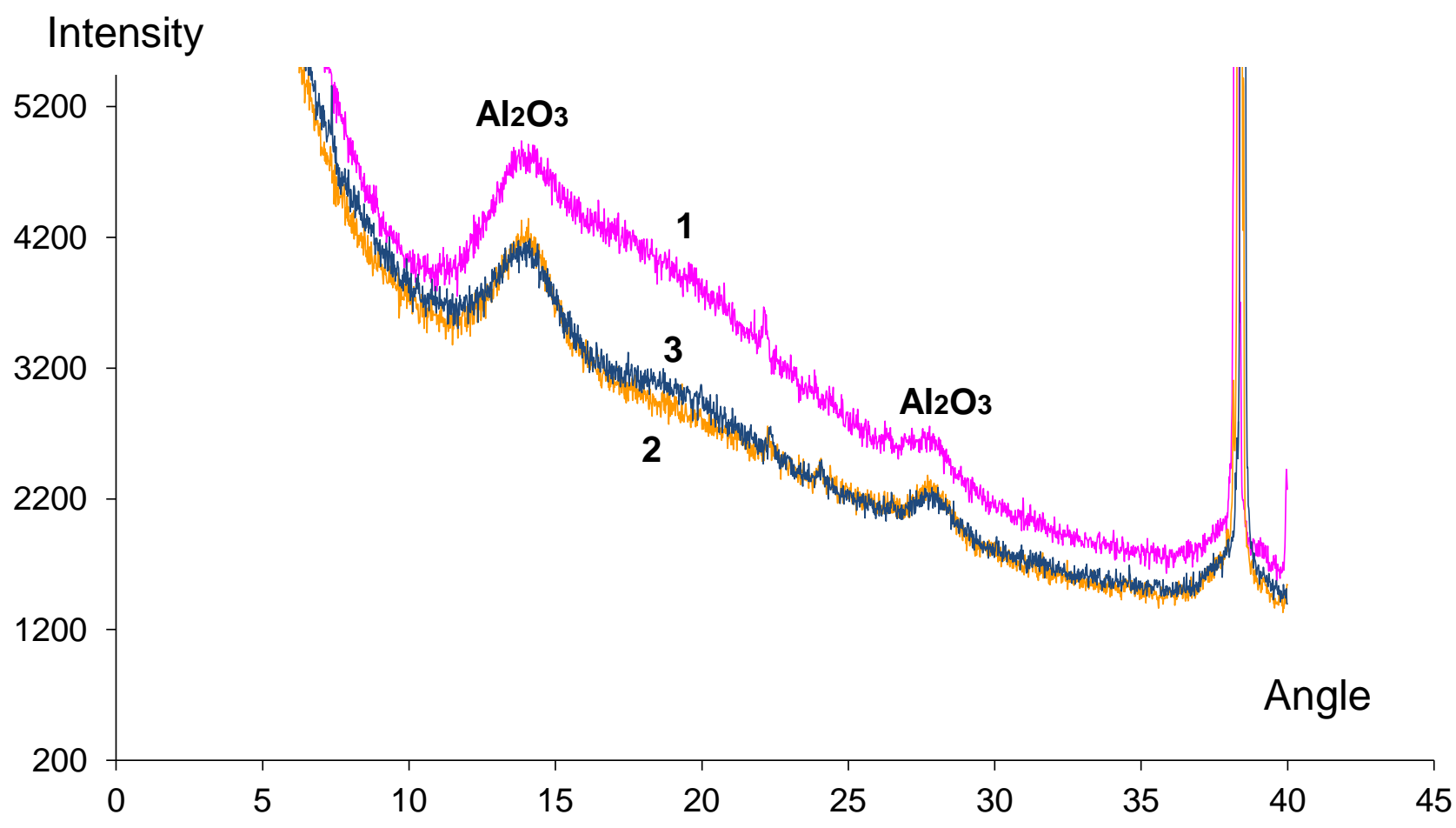

Figure 2. Spectra of X-ray phase analysis of 1010 aluminum alloy with a conversion coating (1) and the subsequent filling in distilled water (2) and in the IFHAN-25 solution (3).

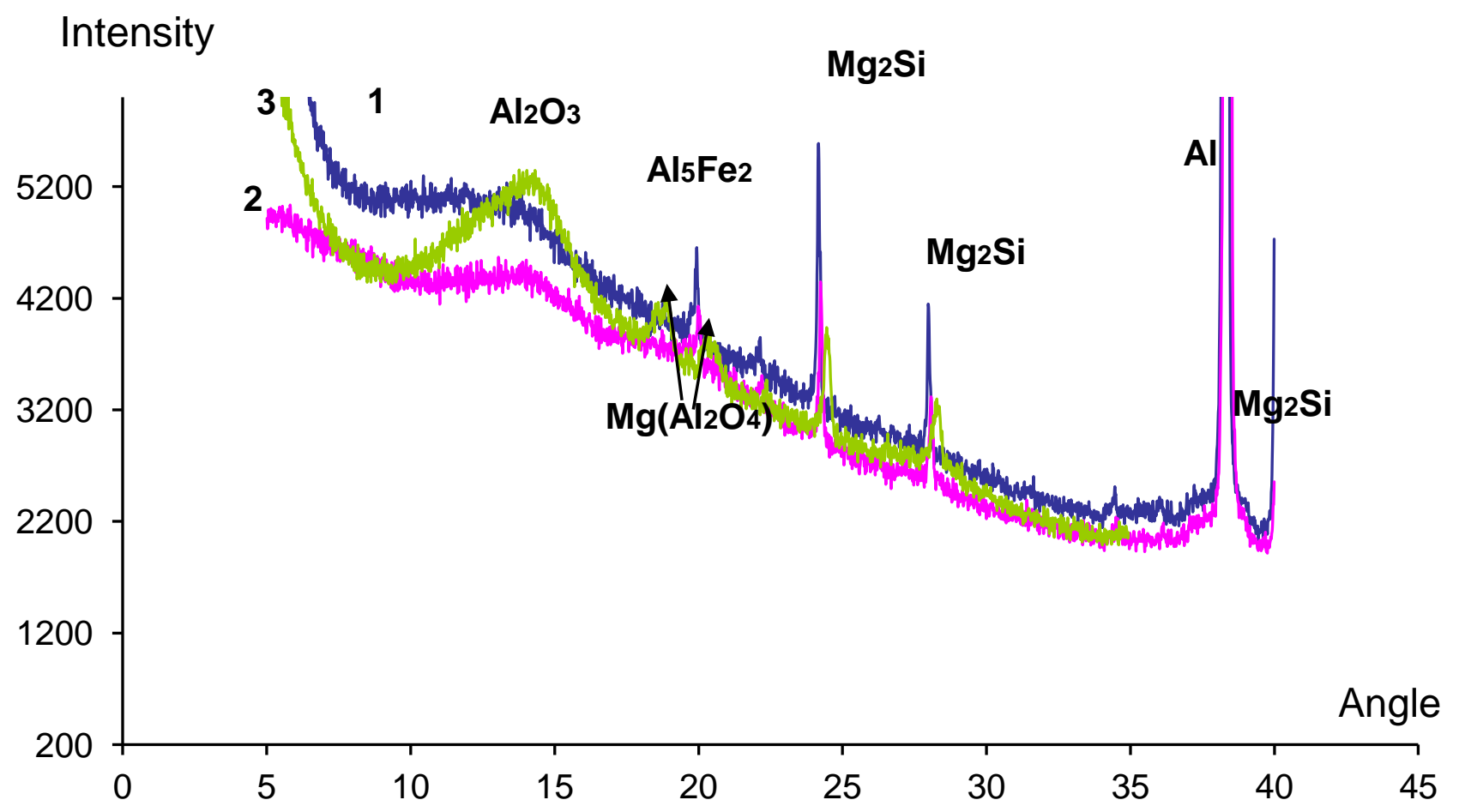

Figure 3. Spectra of X-ray phase analysis of 5154 aluminum alloy with a conversion coating (1) and the subsequent filling in distilled water (2) and in the IFHAN-25 solution (3). 
almost no effect on the phase composition of the coating, only slightly reducing the width of the peak of aluminum oxide, and it is still a highly amorphous phase. Such a coating is similar in protective properties to a non-filled coating (Figure 1). The filling of the coating in a solution of IFKhAN-25 much more strongly influenced by: peak phase of aluminum oxide becomes more pronounced, and therefore less amorphous. Also after filling two small peaks of magnesium-aluminum oxide are clearly distinguished. In this case, the effect of corrosion inhibitor as a compound with surface-active properties on the process of hydration (crystallization) of surface oxides is observed. This, along with the inhibitor adsorption, increases the protective properties of the coating.

The initial coating on a silicon-containing alloy 6063 is also characterized by weak protective properties and the magnitude of the local anode activation potential close to the uncoated alloy (Figure 1). This is not only due to the high porosity of the oxide film, but also due to the multiphase heterogeneous structure of the coating, which is confirmed by the presence of magnesium and silicon oxides in it. The diffractogram also shows that it is silicon oxides in the coating that are released in a separate phase (Figure 4) and probably are one of the reasons of weak corrosion resistance of the coating. The hydration of the oxide film in water makes the first peak of aluminum oxide more pronounced, which means that the phase has become less amorphous. Hydration also removes completely the first peak of silicon oxide; the coating becomes less heterogeneous. The latter may be the consequence of the sedimentary nature of this phase, which is destroyed during the filling of the coating. Although this in itself does not increase the corrosion resistance of the oxide film, but these phase changes significantly facilitate the "work" of the inhibitor, as can be seen from Figure 1. During the filling of the CC in the solution of IFKhAN-25 is a deep modification of the structure of the coating, the first peak of aluminum oxide is divided into two phases of aluminum oxide, which indicates the participation of the inhibitor in the process of hydration of the surface oxides.

The more complex composition has the coating obtained in IFHANAL-3 solution on aluminum alloy 2024. It contains oxides of copper, silicon and magnesium, which, as seen from the diffractogram (Figure 5) are isolated in separate phases along with the amorphous phase of aluminum oxide. The filling of such coating in water again contributes to the modification of the phase of aluminum oxide in a less amorphous form. The second phase of aluminum oxide also appears. The filling in the IFKhAN-25 solution produces the same effect, but both phases of aluminum oxide are slightly weaker "crystallize" than in the case of the filling in pure water coating. The filling does not affect the phases of other metals oxides - copper, magnesium and silicon, which suggests that the major part in increasing of the coating protective properties should include by the adsorption of the corrosion inhibitor. 


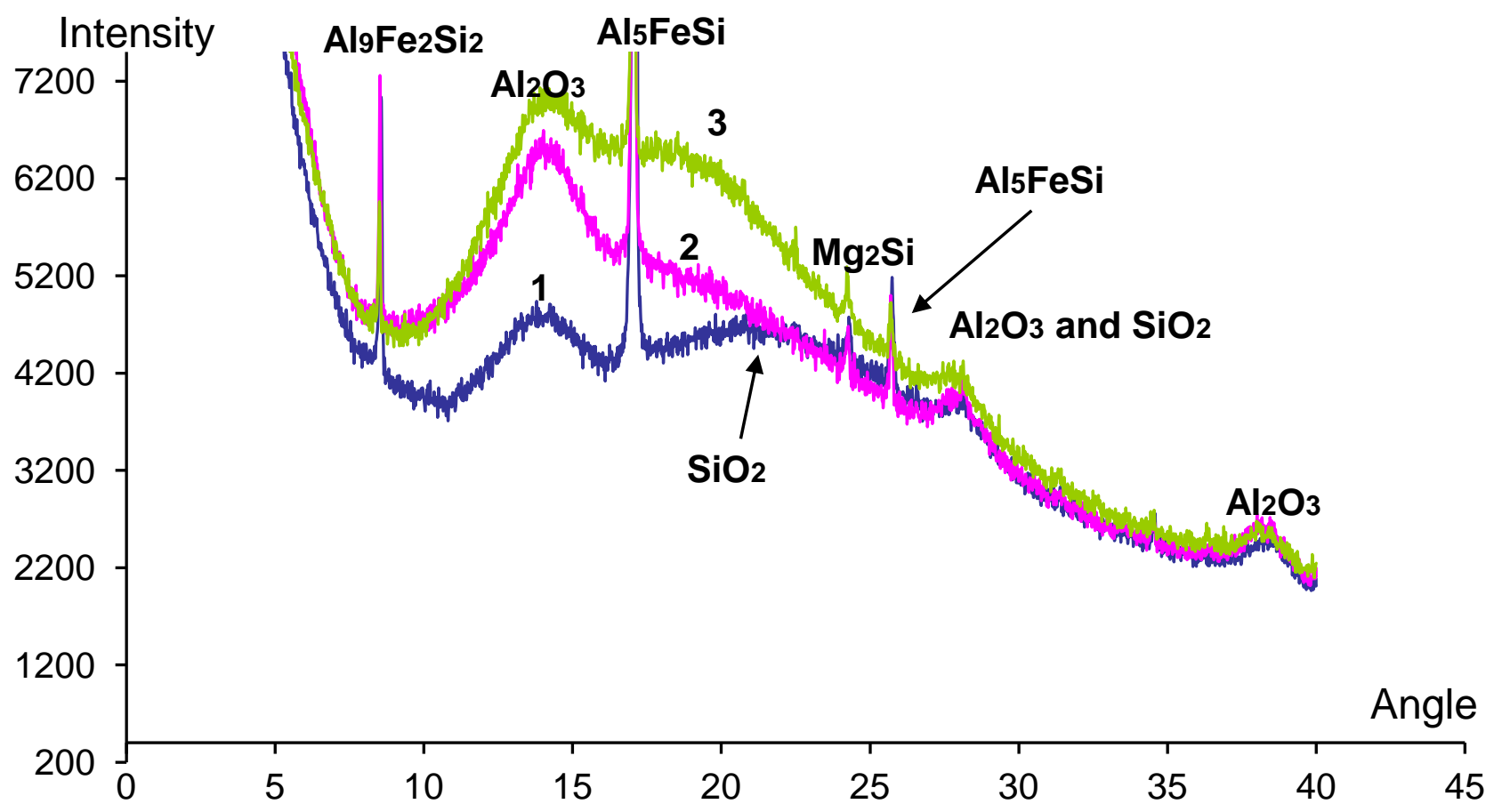

Figure 4. Spectra of X-ray phase analysis of 6063 aluminum alloy with a conversion coating (1) and the subsequent filling in distilled water (2) and in the IFHAN-25 solution (3).

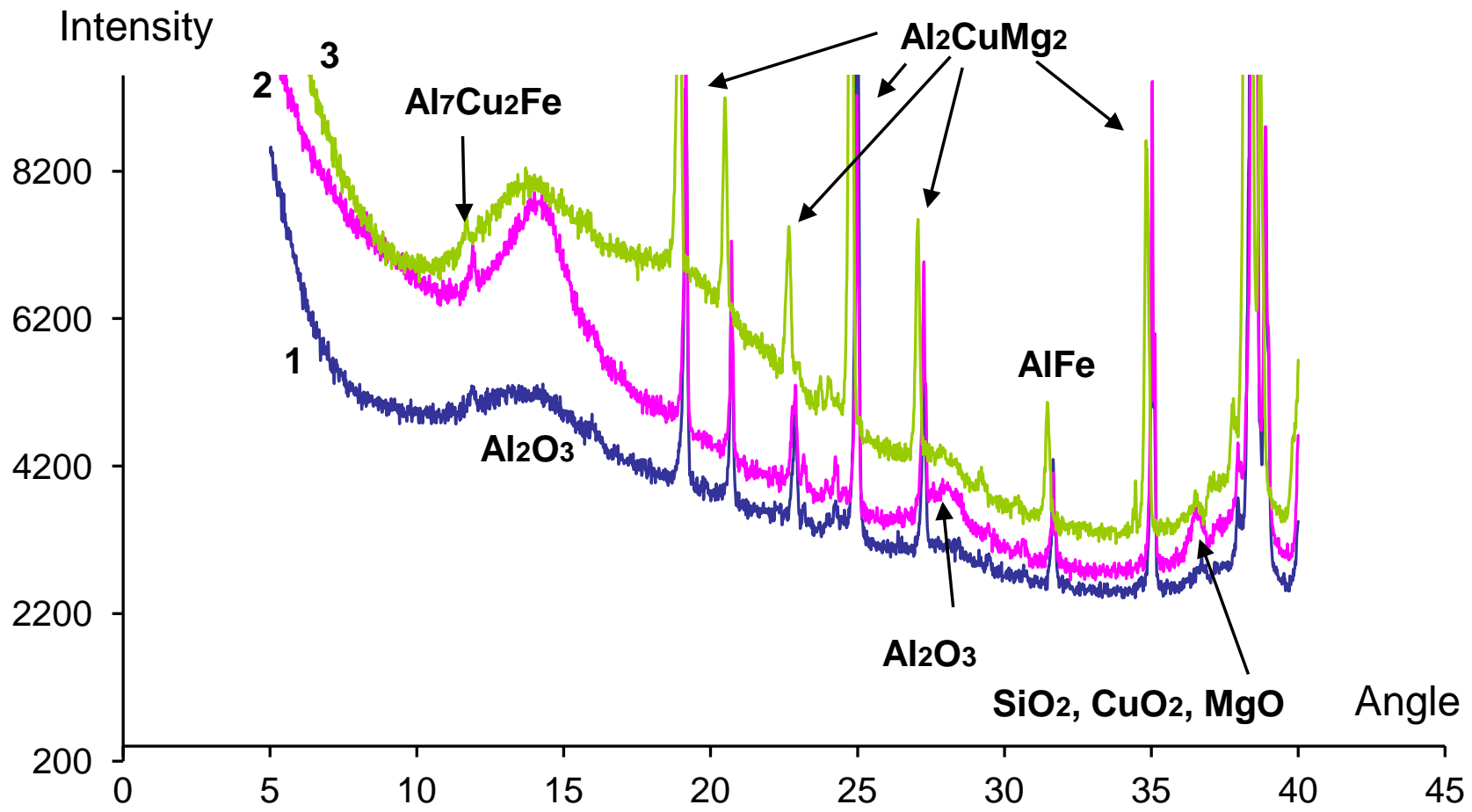

Figure 5. Spectra of X-ray phase analysis of 2024 aluminum alloy with a conversion coating (1) and the subsequent filling in distilled water (2) and in the IFHAN-25 solution (3). 


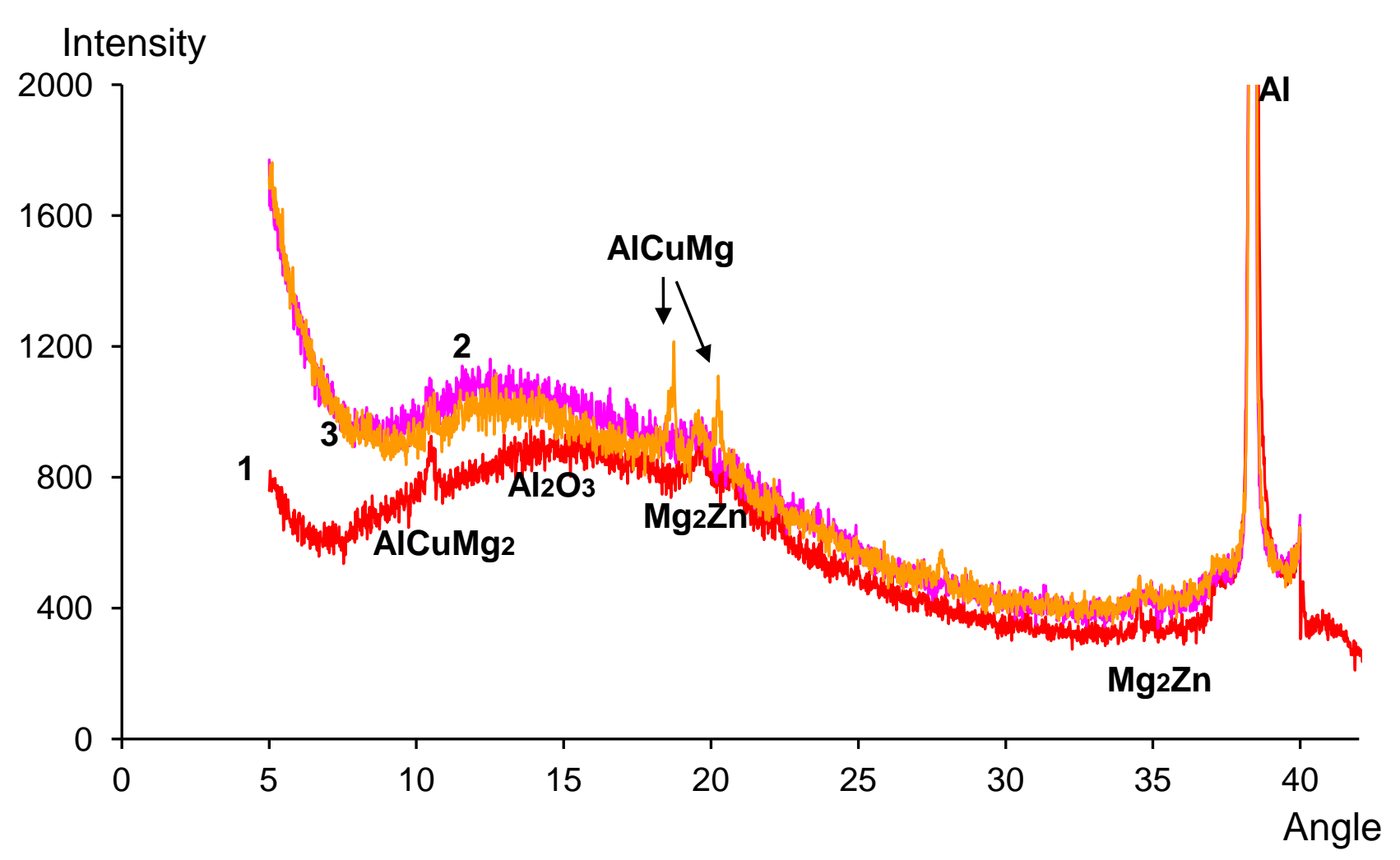

Figure 6. Spectra of X-ray phase analysis of 7075 aluminum alloy without coating (1), with a conversion coating (2) and the subsequent filling in the IFHAN-25 solution (3).

As seen in Figure 6, pre-treatment of alloy 7075-T2 (etching and desmutting), in fact, cleans the surface of the sample from the "additional" phases, so the spectrum is not visible pronounced signals from the substrate. Because of this treatment the coating itself consists of the single phase, which is aluminum oxide. Further filling of the coating in water does not lead to its modification. This is confirmed by the results of polarization measurements, according to which the initial and filled coating do not differ from each other in protective properties. Filling an oxide film in a solution of inhibitor IFKhAN-25 does not affect the phase composition of the coating, so there is an increase in its corrosion properties is solely due to the adsorption of corrosion inhibitor.

\section{Conclusions}

1. The filling of conversion coatings on the investigated alloys modifies the phase state of surface oxides, making them less amorphous.

2. The corrosion inhibitor IFKhAN-25 is directly involved in the process of hydration of the oxides in the conversion coatings on 5154 and 6063 alloys and contributing to the strengthening of their protective properties. During the filling of more complex heterooxide structures on 2024 and 7075 alloys the contribution of the corrosion inhibitor adsorption in the increasing of its protective properties is prevalent. 


\section{Acknowledgements}

The authors express their sincere gratitude to Dr. A.A. Shiryaev for assistance in obtaining and interpreting of diffractograms.

\section{References}

1. S.A. Kulinich, A.S. Akhtar, D. Susac, P.C. Wong, K.C. Wong and K.A.R. Mitchell, On the growth of conversion chromate coatings on 2024-Al alloy, Appl. Surf. Sci., 2007, 253, no. 6, 3144-3153.

2. Y. Liu, P. Skeldon, G.E. Thompson, H. Habazaki and K. Shimizu, Chromate conversion coating on aluminium-copper alloys, Corros. Sci., 2005, 47, no. 2, 341354.

3. L. Juffs, A.E. Hughes, S. Furman and P.J.K. Paterson, The use of macroscopic modelling of intermetallic phases in aluminium alloys in the study of ferricyanide accelerated chromate conversion coating, Corros. Sci., 2002, 44, no. 8, 1755-1781.

4. O. Lunder, J.C. Walmsley, P. Mack and K. Nisancioglu, Formation and characterisation of a chromate conversion coating on AA6060 aluminium, Corros. Sci., 2005,47 , no. 7, 1604-1624.

5. W. Zhu, W. Li, S. Mu, N. Fu and Z. Liao, Comparative study on Ti/Zr/V and chromate conversion treated aluminum alloys: Anti-corrosion performance and epoxy coating adhesion properties, Appl. Surf. Sci., 2017, 405, no. 2, 157-168.

6. C.A. Munson and G.M. Swain, Structure and chemical composition of different variants of a commercial trivalent chromium process (TCP) coating on aluminum alloy 7075-T6, Surf. Coat. Technol., 2017, 315, 150-162.

7. W.-K. Chen, J.-L. Lee, C.-Y. Bai, K.-H. Hou and M.-D. Ger, Growth and characteristics of $\mathrm{Cr}(\mathrm{III})$-based conversion coatings on aluminum alloy, J. Taiwan Inst. Chem. Eng., 2012, 43, no. 6, 989-995.

8. X. Zuo, W. Li, S. Mu, J. Du, Y. Yang and P. Tang, Investigation of composition and structure for a novel $\mathrm{Ti}-\mathrm{Zr}$ chemical conversion coatings on 6063 aluminum alloy, Prog. Org. Coat., 2015, 87, 61-68.

9. P. Santa Coloma, U. Izagirre, Y. Belaustegi, J.B. Jorcin, F.J. Cano and N. Lapena, Chromium-free conversion coatings based on inorganic salts $(\mathrm{Zr} / \mathrm{Ti} / \mathrm{Mn} / \mathrm{Mo})$ for aluminum alloys used in aircraft applications, Appl. Surf. Sci., 2015 345, 24-35.

10. S. S. Golru, M.M. Attar and B. Ramezanzadeh, Morphological analysis and corrosion performance of zirconium based conversion coating on the aluminum alloy 1050, $J$. Ind. Eng. Chem., 2015, 24, 233-244.

11. A. Uhart, J.B. Ledeuil, D. Gonbeau, J.C. Dupin, J.P. Bonino, F. Ansart and J. Esteban, An Auger and XPS survey of cerium active corrosion protection for AA2024-T3 aluminum alloy, Appl. Surf. Sci., 2016, 390, 751-759. 
12. B.Y. Johnson, J. Edington and M.J. O'Keefe, Effect of coating parameters on the microstructure of cerium oxide conversion coatings, Mater. Sci. Eng., 2003, 361, no. $1-2,225-231$.

13. S.V. Oleynik, Yu. I. Kuznetsov and E.M. Maligina, The chemical oxidation of $\mathrm{Al}-\mathrm{Mg}$ alloys in molybdate containing solutions, Korroz.: mater., zashch., 2006, no. 3,38 (in Russian).

14. Yu.I. Kuznetsov, Organic corrosion inhibitors. Where are we? Part I. Adsorption, Korroz.: mater., zashch., 2016, no. 3, 25 (in Russian).

15. S.V. Oleynik, The formation of chromatless conversion coatings on aluminium alloys, The European Corrosion Congress Eurocorr-2010, Moscow, Russia, CD with full texts of papers, paper no. 9287. 